\title{
The Relationship between Self-esteem, Growth Mindset and Depression among Elderly Korean Man and Women
}

\author{
Yun-Jeong Kim ${ }^{1}$, Jin-Suk Hur ${ }^{2 *}$ \\ ${ }^{1}$ Department of Health, Counseling and Welfare, Hanseo University, \\ Republic of Korea \\ ${ }^{2 *}$ Department of Elderly Welfare, Hanseo University, \\ Republic of Korea \\ ${ }^{1}$ twoyun21@hanmail.net, ${ }^{2 *}$ yem5424@nate.com
}

\begin{abstract}
The purpose of this study was to investigate the relationship between self-esteem and depression in men and women aged 65 years or older. To this end, surveys were conducted to a total of 365 men and women aged 65 or older living in Seoul, Gyeonggi, and Seosan from July to August 2019. The subjects of this study are men and women aged 65 or older living in the community. The survey was conducted with the cooperation of the head of the institution and the program manager by visiting the local lifelong learning center, general social welfare center, and general welfare center for the elderly. To achieve the purpose of this study, t-test and correlation analysis were performed using SPSS21.0. The results were followings. First, the growth mindset showed a significant difference according to the sex of the elderly. In other words, older men had higher growth mindsets than older women. However, the difference between self-esteem and depression according to the sex of the elderly was not statistically significant. Second, the higher the self-esteem, the lower the depression in both the elderly. The self-esteem of elderly Korean males negatively affected depression ( $\beta=-.836, p<.001)$. The higher the self-esteem, the lower the depression. The self-esteem of elderly Korean women negatively affected depression ( $\beta=-.803, p<.001$ ), too. In the case of elderly women, as in the case of elderly men, the higher the self-esteem, the lower the depression.
\end{abstract}

Keywords: Self-esteem, Depression, Growth mindset, Aging people, Korean elderly

\section{Introduction}

As of 2017, 21.1\% of the elderly in Korea are experiencing depression, and the rate of depression is increasing with age [1]. In the current situation where aging is rapidly progressing, the number of elderly people suffering from depression will continue to increase. One of the main characteristics of depression is that female seniors have higher depression rate. According to the National Statistical Office [1], as of 2017, 17.2\% of male seniors and $24.0 \%$ of female seniors showed higher levels of depression among female seniors. Therefore, this study is emphasizing the difference in depression among men and women.

If depression is a negative dimension of mental health in old age [2], self-esteem is related to self-image evaluation, mainly positive evaluation, and the degree of self-respect and value [3]. People with high self-esteem have a frame that gives positive meaning to any stimulus, so

Article history:

Received (February 4, 2021), Review Result (March 10, 2021), Accepted (April 10, 2021) 
they always experience a pleasant emotional state, but people with low self-esteem have a frame that gives negative meaning to any stimulus, so they engage in negative emotions [2].

And, Mindset recognizes the possibility of change in intelligence and personality. Goal orientation changes depending on what kind of mindset you have, and you tend to perceive your abilities differently [4]. People with a growth mindset tend to think that they can overcome difficulties and failures and achieve success through hard work and perseverance. This growth mindset has been studied a lot in the field related to learning and has not yet been studied for the elderly.

Nevertheless, despite the importance of self-esteem and growth mindset in elderly depression, studies showing the relationship between these variables were insufficient. Above all, no studies were found that focused on the differences between men and women

The purpose of this study was to investigate the structural relationship between self-esteem and depression in men and women aged 65 years or older.

Specifically, this study is aimed to answer the following questions.

1. Whether there are any differences in self-esteem, depression, and growth mindset between elderly Korean men and women?

2. What is the correlation between self-esteem, depression, and growth mindset for the elderly, male and female?

\section{Method}

\subsection{Research design}

This study is a correlation study to clarify the relationship between self-esteem, growth mindset, and depression in Korean elderly people.

\subsection{Socio-demographic characteristics of the research subject}

The socio-demographic characteristics of 363 elderly people in this study were divided into gender, age, marital status, education level, religion, and place of residence. The male elderly accounted for $36.6 \%$ and the female elderly were $63.4 \%$, with a higher proportion of female elderly. The average age of the elderly was 67.33 year. $78.2 \%$ were married, and $35.0 \%$ were middle school graduates or lower. The elderly without religion accounted for $65.6 \%$ of the total, more than the elderly without religion. $68.6 \%$ lived in urban areas and $31.4 \%$ lived in rural areas, with the number of elderly living in urban areas more than twice as many as those living in rural areas [Table 1].

Table 1. Socio-demographic characteristics of the research subject $(\mathrm{N}=363)$

\begin{tabular}{|c|c|c|c|c|}
\hline \multicolumn{2}{|c|}{} & N & $\%$ & M (S. D) \\
\hline \multirow{3}{*}{ Sex } & Man & 133 & 36.6 & \\
\cline { 2 - 5 } & Woman & 230 & 63.4 & \\
\hline \multirow{2}{*}{ Age } & $60 Y \sim 69 Y$ & 246 & 67.8 & $\begin{array}{c}67.33 \\
(5.792)\end{array}$ \\
\hline
\end{tabular}




\begin{tabular}{|c|c|c|c|c|}
\hline & Over 70Y & 117 & 32.2 & \\
\hline \multirow{2}{*}{ Marital status } & Married & 284 & 78.2 & \multirow{2}{*}{-} \\
\hline & Others & 79 & 21.8 & \\
\hline \multirow{3}{*}{ Education } & $\begin{array}{l}\text { Middle school } \\
\text { graduates or lower }\end{array}$ & 127 & 35.0 & \multirow{3}{*}{-} \\
\hline & $\begin{array}{l}\text { High school } \\
\text { graduates }\end{array}$ & 121 & 33.3 & \\
\hline & $\begin{array}{l}\text { Over college } \\
\text { graduates }\end{array}$ & 115 & 31.7 & \\
\hline \multirow{2}{*}{ Religion } & Yes & 125 & 34.4 & \multirow{2}{*}{ - } \\
\hline & No & 238 & 65.6 & \\
\hline \multirow{3}{*}{$\begin{array}{l}\text { Economic } \\
\text { conditions }\end{array}$} & $\mathrm{Bad}$ & 57 & 15.7 & \multirow{3}{*}{$\begin{array}{c}3.21 \\
(.782)\end{array}$} \\
\hline & Similar & 176 & 48.5 & \\
\hline & Good & 130 & 35.8 & \\
\hline \multirow{3}{*}{ Health conditions } & Bad & 51 & 14.0 & \multirow{3}{*}{$\begin{array}{c}3.37 \\
(.849)\end{array}$} \\
\hline & Similae & 142 & 39.1 & \\
\hline & Good & 170 & 46.8 & \\
\hline \multirow{2}{*}{ Residence } & Urban & 249 & 68.6 & \multirow{2}{*}{ - } \\
\hline & Rural & 114 & 31.4 & \\
\hline
\end{tabular}

\subsection{Research data collection procedure}

The subjects of this study are men and women aged 65 or older living in the community. For data collection, surveys were conducted in July and August 2019 targeting 363 elderly people living in Seoul, Gyeonggi, and Seosan. The survey was conducted with the cooperation of the head of the institution and the program manager by visiting the local lifelong learning center, general social welfare center, and general welfare center for the elderly. 


\subsection{Measurement}

The subjects of this study are men and women aged 65 or older living in the community. For data collection, surveys were conducted in July and August 2019 targeting 363 elderly people living in Seoul, Gyeonggi, and Seosan. The survey was conducted with the cooperation of the head of the institution and the program manager by visiting the local lifelong learning center, general social welfare center, and general welfare center for the elderly.

\subsubsection{Self-esteem}

The self-esteem scale was used by translating the scale of Rogenberg [7]. It is a 10-item, 5point Likert-type scale, and questions 3, 5, 8, 9, and 10 were recoding. This scale consists of 4 mindset questions about changes in human intelligence (IQ) and 4 questions about personality changes. The reliability Cronbach's alpha value was .809 .

\subsubsection{Growth mindset}

The growth mindset scale was developed by Deweck (2006) and adapted by Lee, Park and Hwang [8]. This scale consists of 4 mindset questions about changes in human intelligence (IQ) and 4 questions about personality changes. It is a total of 8 questions and a 5-point Likert scale. The reliability Cronbach's alpha value was .870 .

\subsubsection{Depression}

As a tool for measuring depression, the CES-D scale developed by Radloff [9] was translated and used. It is a 10-item, 5-point Likert scale. The reliability Cronbach's alpha value was .869.

\subsection{Analysis method}

To achieve the purpose of this study, t-test and correlation analysis were performed using SPSS21.0.

\section{Results}

\subsection{Differences in self-esteem, growth mindset, and depression between Korean man and woman elderly}

[Table 2] presents the results of analyzing the differences in self-esteem, growth mindset, and depression according to gender in Korean elderly using t-test. As shown in [Table 1], the growth mindset showed a significant difference according to the sex of the elderly. In other words, older men had higher growth mindsets than older women. However, the difference between self-esteem and depression according to the sex of the elderly was not statistically significant.

As the difference in growth mindset between male and female seniors was statistically significant, it was predicted that there would be a difference between males and females in the path leading to depression through the elderly's self-esteem through the growth mindset. Therefore, in the subsequent analysis, the elderly men and elderly women were analyzed separately.

Table 2. Differences between men and women in self-esteem, growth mindset, and depression $(\mathrm{N}=363)$ 


\begin{tabular}{|c|c|c|c|c|c|}
\hline & & $\mathrm{N}$ & M & S. D & $\mathrm{t}$ \\
\hline \multirow{2}{*}{ Self-esteem } & Man & 133 & 3.374 & .478 & \multirow{2}{*}{-.759} \\
\hline & Woman & 230 & 3.416 & .510 & \\
\hline \multirow{2}{*}{ Growth mindset } & Man & 133 & 3.200 & .529 & \multirow{2}{*}{2.123} \\
\hline & Woman & 230 & 3.068 & .591 & \\
\hline \multirow{2}{*}{ Depression } & Man & 133 & 2.440 & .635 & \multirow{2}{*}{.164} \\
\hline & Woman & 230 & 2.428 & .691 & \\
\hline
\end{tabular}

\subsection{Correlation between self-esteem, growth mindset, and depression in Korean man and woman elderly}

To examine relationship among variables self-esteem, growth mindset, depression of the Korean old man, this study conducted correlation analysis, and found out that correlations among all the variables were significant [Table 2].

In both the elderly men and women, the higher the self-esteem and the higher the growth mindset, the lower the depression. In addition, the higher the self-esteem, the higher the growth mindset. In addition, the correlation coefficient is from .235 to .329 for older males and .170 to .593 for older females, so there is no risk of multicollinearity between variables.

Table 3. Correlation between variables $(\mathrm{N}=363)$

\begin{tabular}{|c|c|c|c|c|}
\hline & & Self-esteem & Growth mindset & Depression \\
\hline \multirow{3}{*}{$\begin{array}{l}\text { old man } \\
(n=133)\end{array}$} & Self-esteem & & & \\
\hline & Growth mindset & $.358^{* * * *}$ & & \\
\hline & Depression & $-.629^{* * * *}$ & $-.235^{* *}$ & \\
\hline \multirow{3}{*}{$\begin{array}{l}\text { old woman } \\
(\mathrm{n}=230)\end{array}$} & Self-esteem & & & \\
\hline & Growth mindset & $.170^{* * *}$ & & \\
\hline & Depression & $-.593^{* * *}$ & $-.270^{* * *}$ & \\
\hline
\end{tabular}

\subsection{The Effect of Self- esteem on the on Depression in Korean men and women elderly}

\subsubsection{Old man}

The self-esteem of elderly Korean males negatively affected depression $(\beta=-.836, p<.001)$. The higher the self-esteem, the lower the depression [Figure 1]. 


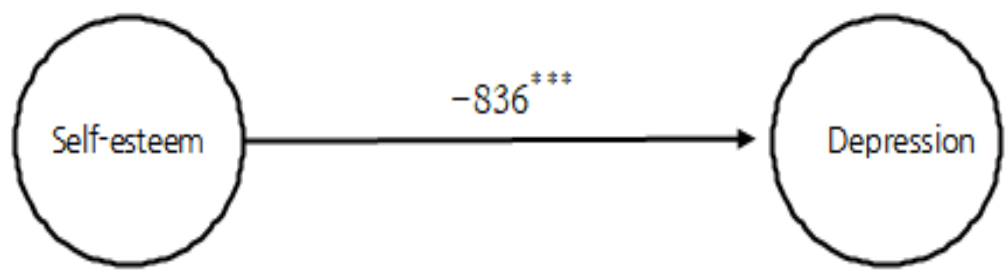

Figure 1. The effect of the self-esteem on the depression of the Korean old man

\subsubsection{Old woman}

The self-esteem of elderly Korean women negatively affected depression $(\beta=-.803, p<.001)$. The higher the self-esteem, the lower the depression (Figure 2).

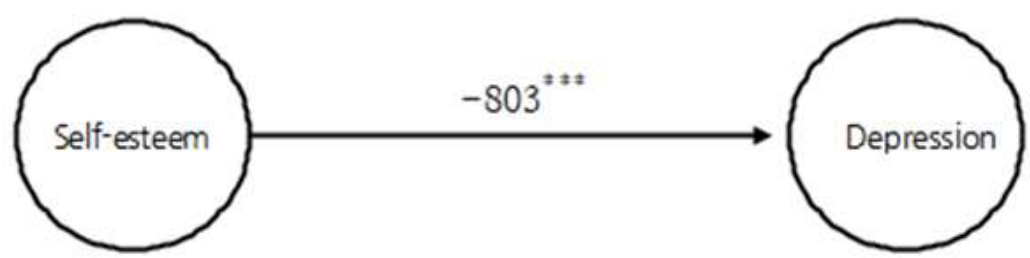

Figure 2. The effect of the self-esteem on the depression of the Korean old woman

\section{Discussion}

The purpose of this study was to investigate the structural relationship between self-esteem and depression in men and women aged 65 years or older. A survey was conducted on 363 elderly people living in Seoul, Gyeonggi, and Seosan in July and August 2019.

First, male elderly had higher growth mindset than female elderly. The gender differences between self-esteem and depression were not statistically significant. The gender differences between self-esteem and depression were not statistically significant. In the case of depression, female elderly is generally higher than male elderly [8]. The reason that the difference in depression between male and female elderly in this study was not statistically significant. We can assume the reason that this is because the survey was taken in welfare centered community. That is, because social disconnection affects the depression of elderly females, and the elderly with active social participation have lower levels of depression than those who do not.

Second, the higher the self-esteem, the lower the depression in both the elderly men and the elderly women in Korea. These results are in the same context as previous studies [3], [10], which revealed the negative relationship between self-esteem and depression.

Third, it is suggested that self-esteem must be improved in order to reduce depression of elderly.

In this study, we identified the relationship between depression, self-esteem, and growth mindset, which had been lacking in academic interest, and revealed that there is a difference between men and women in this relationship. It also revealed that self-esteem in old age has an effect on depression. Nevertheless, since the mediating effect or the moderating effect of the growth mindset on the relationship between self-esteem and depression has not been identified, an analysis on this will be needed in future studies. In addition, since the data in this study are limited in Seoul, Gyeonggi, and Seosan, attention should be paid to generalization of the study. 


\section{References}

[1] Kostat "Top 100 indicators of Kosis (Elderly depression)," https://kosis.kr/conts/nsportalStats/nsportalStats_0102Body.jsp;jsessionid=Jw3LneT1211 ApvjALXYMCydF KOj9DWutKpjyE3pr3QzhLp11V0Tkn9jTjNeJRmq5.STAT_WAS2_servlet_engine4?menuId=13\&NUM=11 00\&cntUpdate $=$ Y, Jan 13, (2021)

[2] S. A. Lee, G. M. Lee, "A study on the major factors influencing the depression among the elderly in rural area," Journal of the Korea Gerontological Society, vol.22, no.1, pp.209-226, (2002)

[3] M. Rosenberg, "Self-concept and psychological well-being in adolescence," The Development of the Self, vol.1, pp.205-246, (1985)

[4] M. Tamir, O. P. John, S. Srivastava, and J. J. Gross, "Implicit theories of emotion: Affective and social outcomes across a major life transition,” Journal of Personality and Social Psychology, vol.92, no.4, pp.731744, (2007)

[5] J. L. Schleider, J. L. Burnette, L. Widman, C. Hoyt, and M. J. Prinstein, "Randomized trial of a single-session growth mind-set intervention for rural adolescents internalizing and externalizing problems," Journal of Clinical Child and Adolescent Psychology, vol.49, no.5, pp.660-672, (2020)

[6] H. S. Schroder, M. M. Yalch, S. Dawood, C. P. Callahan, M. B. Donnellan, and J. S. Moser, "Growth mindset of anxiety buffers the link between stressful life events and psychological distress and coping strategies," Personality and Individual Differences, vol.110, pp.23-26, (2017)

[7] M. Rosenberg, "Rosenberg self-esteem scale (RSE). Acceptance and commitment therapy," Measure's package, vol.61, (1965)

[8] C. S. Lee, S. U. Park, and Y. K. Hwang, "The structural relationship between mother's parenting stress and child's well-being: The mediating effects of mother's growth mindset and hope," Indian Journal of Science and Technology, vol.9, no.36, pp.1-6, (2016)

[9] L. S. Radloff, "The CES-D scale: A self-report depression scale for research in the general population," Applied Psychological Measurement, vol.1, no.3, pp.385-401, (1977)

[10] R. W. Tafarodi, and W. B. Swann Jr, "Self-linking and self-competence as dimensions of global self-esteem: initial validation of a measure," Journal of Personality Assessment, vol.65, no.2, pp.322-342, (1995) 
The Relationship Between Self-esteem, Growth Mindset and Depression Among Elderly Korean Man and Women

This page is empty by intention. 